\title{
Two types of short-term visual storage'
}

\author{
LIONEL STANDING, RALPH NORMAN HABER, ${ }^{2}$ MICHAEL CATALDO,${ }^{3}$ AND B. DENNIS SALES
} UNIVERSITY OF ROCHESTER

Seven-letter words were flashed repetitively at various durations above and below the recognition threshold for single flashes. One form of a short-term storage effect was studied by measuring the interstimulus interval between flashes at which $S$ reported that the stimulus became phenomenally discontinuous in time. Storage times reached a maximum of about $300 \mathrm{msec}$ in this task. A second form of storage effect was measured by decreasing the interstimulus interval until $S$ could correctly recognize a repeated stimulus whose duration was below the single-flash recognition threshold; this effect extended to $900 \mathrm{msec}$ in some cases. Each of these effects was reliably obtained for both rare and frequent words. Both forms of storage were increased by providing a dark rather than a lighted adapting field between presentations of the test stimulus. Implications for information processing of brief displays are discussed.

Haber and Standing (1969) have shown that if an outline black circle is presented repeatedly, so that it is on for 4 to $200 \mathrm{msec}$, and then off for some period, during which an adapting field of the same luminance appears, Ss will report that the circle never completely fades away if the duration of the adapting field is less than approximately $250 \mathrm{msec}$. This result provides a direct estimate of the duration of visual persistence, as compared to the very indirect procedures of Sperling (1960) and Averbach and Coriell (1961). Haber and Standing also found that persistence is slightly longer for low as compared to high luminance exposures and that it may be increased to over $400 \mathrm{msec}$ by reducing the luminance of the adapting field to zero. Finally, they showed the persistence effect could not be entirely retinal, since the same persistence was found when the circle was presented to the two eyes alternately.

One purpose of the present study was to examine this effect with rare and frequent English words as stimuli, presented for durations above and below the recognition threshold. It was expected that these more complex stimuli would still yield the same duration of visual persistence as the circle stimulus.

A second purpose concerned the relation of persistence to recognition. In a series of studies (e.g., Haber, 1965; Hershenson \& Haber, 1965) it had been shown that the clarity of a word was increased with well-spaced repeated exposures, even in the absence of any changes in duration or luminance. No increase was found, however, if the exposure were set at, or even slightly above, the detection threshold (Haber \& Hershenson, 1965). It was necessary that $S$ could see one or more letters on the first flash for him to be able to see them all after 5 to 10 flashes, each separated by five or more seconds. Given the visual persistence effect noted above, it is possible that with more closely spaced flashes, even subliminal presentations may become clear and recognizable. Therefore, in a second task, the same words were repeatedly shown at various energy levels below threshold, and $\mathrm{S}$ was asked whether he could recognize the word being flashed. Both parts of the experiment (the perceived persistence measurement and the recognition task) were performed with rare and with frequent words, and for lighted as well as dark adapting field conditions.

\section{Subjects}

Twenty graduate and undergraduate students from the
University of Rochester, with $20 / 20$ or corrected vision, served as paid Ss. Most Ss had previous experience in tachistoscopic tasks; all were unaware of any specific experimental hypotheses.

\section{Apparatus and Stimuli}

The study employed a Scientific prototype two-channel tachistoscope (Model 800E). All durations and luminances were monitored by means of a photomultiplier, and ecalibrated where necessary. The test field luminance was $.0 \mathrm{~mL}$ throughout the study, while the adapting field was 1.0 or $0 \mathrm{~mL}$, according to the condition employed. Testing was performed in a dark room. Two very faint fixation points, separated by $1 \mathrm{deg}$, were placed immediately above and below the test stimulus.

The stimuli comprised two sets of 100 seven-letter emotionally-neutral English words. The two sets ("rare" and "frequent," respectively) were selected from Parts 2 and 1(AA) of the Thorndike-Lorge (1944) word list; the corresponding frequencies of usage are less than 1 per million and over 100 per million.

The stimulus words were typed in black on grey paper to provide a contrast ratio of $30 \%$. The viewing distance was $80 \mathrm{~cm}$; the height and width of the words were equivalent to visual angles of $0.36 \mathrm{deg}$ and $1.93 \mathrm{deg}$, respectively. The individual letters subtended visual angles of $0.21 \mathrm{deg}$.

\section{Procedure}

Each $S$ was randomly assigned to a frequent or a rare word condition (10 Ss in each treatment). Within each condition he was tested on the two adapting field luminances, all testing on one luminance being completed before the other was begun. The order of the luminances was randomized between Ss. For each adapting field luminance, the sequence followed was first the measurement of the S's single flash threshold, followed by measurement of visual persistence, and then recognition measurement. About $5 \mathrm{~h}$ of testing were required for each $\mathrm{S}$.

\section{Measurement of Recognition Threshold}

The $S$ was first adapted to the background luminance ( 1 or $0 \mathrm{~mL}$ according to the experimental condition) and then given 10 practice trials similar to the threshold measurement procedure. The threshold duration for recognition of the words was then determined using a staircase method with steps of $10 \mathrm{msec}$ duration. Each trial comprised 10 presentations of the test stimulus (at intervals of $10 \mathrm{sec}$ or longer) to ensure that an asymptotic level of recognition had been reached. The recognition threshold was defined as the duration corresponding to a 0.50 probability of correct recognition of the word. A different word was used as a test stimulus on each trial. The $\mathrm{S}$ gave his response verbally after the 10 flashes. The $\mathrm{S}$ initiated each stimulus presentation by means of a switch upon verbal instruction from $\mathrm{E}$. The $\mathrm{S}$ was told to observe between the fixation points and then to guess the stimulus word after 10 presentations. All Ss were informed that only seven-letter, non-taboo English words would be used as stimuli throughout the experiment.

\section{Direct Ratings of Visual Persistence (Task 1)}

Immediately after determining the recognition threshold, a test stimulus was presented in continuous alternation with the adapting field. The duration of the stimulus was set at some mul- 
tiple of the recognition threshold for the $\mathrm{S}$ being tested. Nine values of duration between 0.2 and 3.0 times the recognition threshold in milliseconds were employed for the test stimulus, in random order. For each test stimulus duration the duration of the adapting field was varied, using the descending method of limits, to determine the value at which the $S$ judged the test stimulus considered as a form to be just phenomenally continuous in time rather than a series of discrete stimulus presentations. Steps of $20 \mathrm{msec}$ were used starting at an adapting field duration of $500 \mathrm{msec}$. Four descending series of adapting field duration were used at each stimulus field duration to yield four estimates of visual persistence. The $S$ was instructed to fixate the test stimulus and to indicate whether it was continuous or discontinuous. It was emphasized that flicker of the background field and possible apparent movements of the test stimulus were irrelevant to the judgment and that the persistence of the form need not be perfect, provided it was discriminably above zero, to justify the response of "continuous."

\section{Recognition Measurement of Repetitive Stimuli (Task 2)}

The four lowest durations (between 0.2 and 0.8 times the threshold duration) were used to set the duration of the test stimulus. The duration of the adapting field was set at $1500 \mathrm{msec}$ and reduced through a descending method of limits in $50 \mathrm{msec}$ steps. At each step the cycle repeated for a number of times while $S$ guessed the word. The series was stopped at the duration at which the $S$ first correctly identified the test word. The $\mathrm{S}$ was required to respond within $5 \mathrm{sec}$. Four different determinations were made at each test stimulus duration. Before each of the four words was presented, a check was made that the word in fact was below threshold duration. Ten repetitions of the word at intervals of $10 \mathrm{sec}$ were given, and the word was discarded if the $S$ was able to guess it correctly at any of those flashes. This occurred occasionally when the test was set at 0.8 times the threshold duration but never on shorter durations.

\section{RESULTS}

The mean single-flash recognition thresholds for the rare and the frequent words employed, under lighted and dark adapting field conditions, are given in Table 1. The standard deviation of these thresholds was $33.7 \mathrm{msec}$. An analysis of variance indicated that neither the rare-frequent $(\mathrm{F}=4.1, \mathrm{df}=1 / 7, \mathrm{p}=.08)$ nor the dark-light factor $(\mathrm{F}<1)$ significantly affected these thresholds, although the frequency effect was moderately strong.

The mean values obtained in Tasks 1 and 2, representing respectively the adapting field duration at which perceived visual persistence and correct recognition of the stimulus occurred, are illustrated in Fig. 1 for rare words and Fig. 2 for frequent words.

Analyses of variance were performed upon the thresholds obtained in Tasks 1 and 2 separately. The first analysis (of somewhat limited value due to very inhomogeneous variances which increased with the mean threshold values) indicated that Task-1 thresholds were significantly affected by test stimulus duration, adapting field luminance, and word frequency

Table 1

Mean Single-Flash Recognition Thresholds for Rare and for Frequent Words under Lighted and Dark Adapting Field Conditions. The Threshold Test Stimulus Duration is given in Msec.

\begin{tabular}{lccc}
\hline & & \multicolumn{2}{c}{ Test stimulus } \\
& & Rare words & Frequent words \\
\hline $\begin{array}{l}\text { Adapting } \\
\text { field }\end{array}$ & $0 \mathrm{~mL}$ & 111.0 & 76.9 \\
luminance & $1 \mathrm{~mL}$ & 116.9 & 90.6 \\
\hline
\end{tabular}

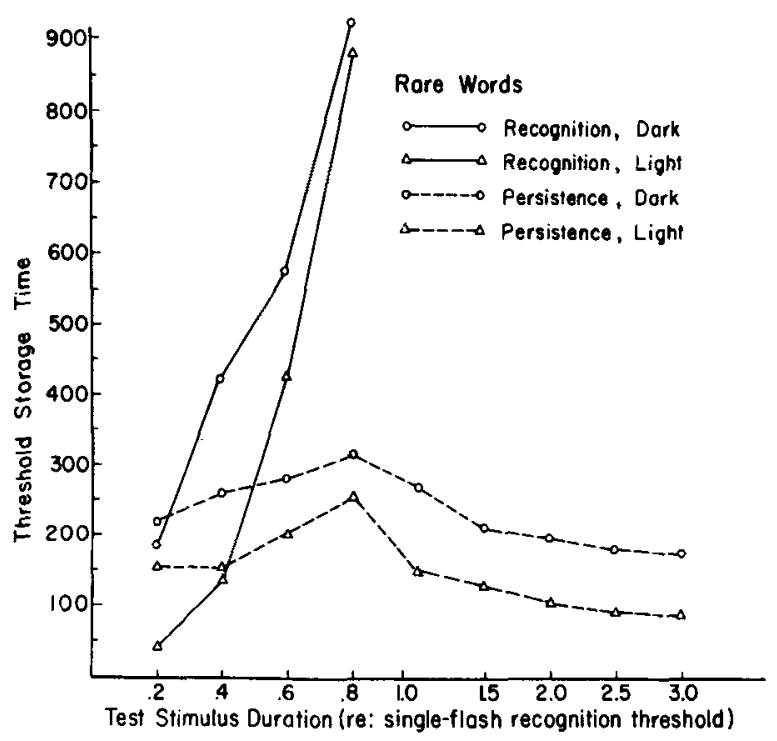

Fig. 1. Mean adapting field durations (in milliseconds) for threshold in Task 1 (perceived persistence) and Task 2 (recognition), as a function of test stimulus duration. The data are for rare words under dark and lighted adapting field conditions. Test stimulus durations are relative to the single-flash recognition threshold (mean values: $111.0 \mathrm{msec}$ with dark and $116.9 \mathrm{msec}$ with lighted adapting field).

$(\mathrm{F}=151, \mathrm{df}=8 / 605 ; \mathrm{F}=493, \mathrm{df}=1 / 605 ; \mathrm{F}=47.9$, $\mathrm{df}=1 / 605 ; \mathrm{p}<.001$ in all cases). The second analysis showed that Task-2 thresholds were affected by the same factors $(\mathrm{F}=477, \mathrm{df}=3 / 240 ; \mathrm{F}=100, \mathrm{df}=1 / 240 ; \mathrm{F}=160$, $\mathrm{df}=1 / 240 ; \mathrm{p}<.001$ in all cases).

\section{DISCUSSION}

The data cleariy show that sizeable "visual storage" effects were obtained in this study. For both tasks, the effects of the test stimulus extend over an interflash interval considerably longer than the duration of the test stimulus. In Task 1, for example, an 80-msec test stimulus is still seen as phenomenally continuous in time even when $300 \mathrm{msec}$ of darkness elapses between flashes of the word. In general terms, this accords with the findings of Sperling (1960) that the perceived duration of a stimulus may greatly exceed its physical duration. It is also clear that the two tasks employed here yield measures of storage effects which differ both in their absolute magnitude and in their functional relationship to test stimulus duration. While there is a convergence between the two measures at short stimulus durations (Figs. 1 and 2), the upper portions of these curves show striking deviations between the two tasks.

We feel that different mechanisms are operative in the above two types of storage effect (although both are, of course, operative upon the same stimulus trace). This hypothesis is reinforced by the fact that the direct measures of visual persistence obtained in Task 1 bear some similarity to values previously obtained by direct judgments (Haber \& Standing, 1969), which in turn agreed with the values of Sperling (1960) and Averbach and Coriell (1961). Each of these studies depends in some manner upon the legibility of the stimulus trace at a time subsequent to the presentation of the stimulus, and all have yielded values for the duration of this visual storage in the range of $200-300 \mathrm{msec}$. Task 2, however, depends upon the ability of the residual stimulus trace to raise a subsequent presentation of the stimulus to the recognition threshold, and indicates storage effects extending up to $900 \mathrm{msec}$.

The apparently novel storage effect of Task 2 can be 


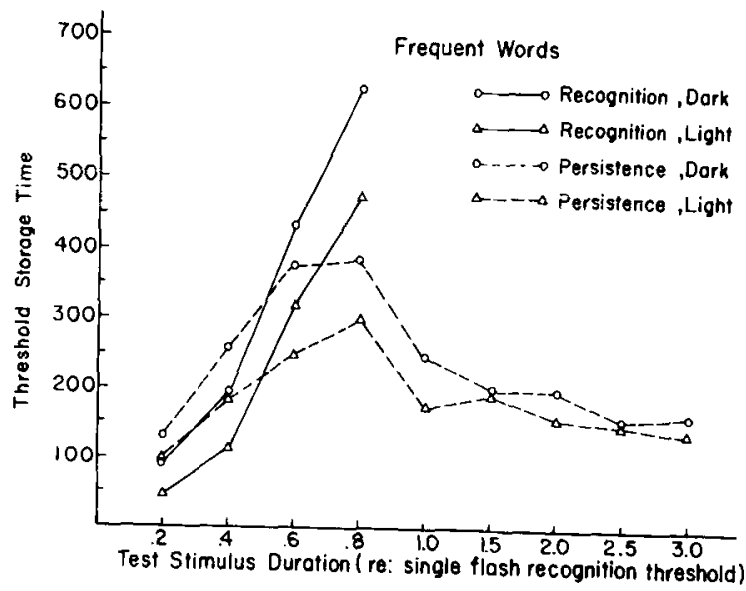

Fig. 2. Data as for Fig. 1, but with frequent words as test stimuli. (Mean single-flash recognition threshold: $76.9 \mathrm{msec}$ with dark and $90.6 \mathrm{msec}$ with lighted adapting field.)

described as subliminal in two senses; first, the test stimulus is below the single-flash recognition threshold (even after many well-spaced presentations); second, this storage process occurs at interflash intervals for which no continuous percept of the test stimulus persists between stimulus presentations. Though some process must persist between flashes, it is below the threshold of awareness.

Three classes of explanation suggest themselves for the long storage effect shown in Task 2, based upon artifactual processes, sensory summation, and information processing factors. The effect could result from improved fixation or accommodation during rapid stimulation, from pupil responses, or from $\mathrm{S}$ sometimes guessing the word correctly at a very long adapting field duration without perceiving it, thus leading to a spuriously high estimate of the storage time. We have examined these possibilities without success, however, and so far are unable to identify any such mediating mechanism adequate to account for the effect. The guessing hypothesis in particular is disproved by the data; the median scores were almost identical to the means, and the distribution of storage times (for both tasks) was almost normal with only a slight positive skew.

Sensory summation in the manner described by Bloch's law is not a tenable explanation for this storage effect, since the visual system usually summates luminance over little more than 100 msec (Barlow, 1958). While Kahneman (1966) has shown that temporal summation of visual information depends upon the stimulus conditions, and indeed may of ten extend up to $400 \mathrm{msec}$ for acuity tasks involving Landolt $\mathrm{Cs}$, this value is still too low to account for our data. (Interestingly, however, Kahneman also reports one case, using a white-on-grey stimulus presentation, where the critical duration is almost 1000 msec.) Possibly an examination of the difference between summation in the course of one stimulus presentation (studied by measuring its threshold luminance as a function of the stimulus duration), as opposed to summation between successive presentations (demonstrated here by repeated flashing of a subthreshold stimulus) would explain this difference. However, in the case of flash stimuli, at least, Bloch's law applies equally to single- or multiple-stimulus summation (Davy, 1952). There is the further problem that the stimuli here do not summate according to the perceptions of the $\mathrm{S}$.

A possible (though speculative) form of explanation of a sensory-summation type appears to be as follows: Stimulation by a test form causes both excitatory and lateral inhibitory processes in the visual system. There is probably a difference in the speed of these two processes (which may be responsible for the characteristics of the Mach bands phenomenon), and it appears that inhibitory processes are the slower (Ratliff, 1965). The lateral inhibitory afterdischarge following a brief stimulus presentation may be too slow to affect the perception of that stimulus greatly, but it will persist, much more than the excitatory processes, and thus may summate with the inhibitory processes set up by the next stimulus presentation, a few hundred milliseconds later. We postulate that this summed inhibition may lead to reciprocal enhancement of lateral excitatory processes, and thus cause a sharpening of the test stimulus trace. The time constants of neural activity necessary for integrative effects over the intervals found here do not appear to be implausibly large. Ratliff (1965, p. 116) describes summation of inhibitory processes over an interval of $1.0 \mathrm{sec}$. Further, Jung (1961) gives data on the residual cortical activity following brief photic stimulation which indicate activation and inhibition phases lasting nearly a second. These results (from the cat) are correlated by Jung with the phases of subjective afterimages in man.

A third type of explanation of the storage effect, in terms of information processing factors, would imply that the primary sensory impression or short-term visual storage (Haber, 1969) of the test stimulus is not improved by the repetitive stimulation used in Task 2 , but that the "read-out" or encoding whereby information is transferred from this image to a short-term memory is somehow facilitated. Haber (1965) has emphasized how factors such as knowledge of the stimulus, or past experience with it, can apparently facilitate encoding processes, leading to a striking increase in the clarity of tachistoscopic stimuli. There may be a number of ways in which the accuracy or skill in processing information from a constant primary visual image can be improved. However, the increased storage times in Task 2 when the adapting field is darkened (similar to Sperling's finding, 1960) suggests that purely sensory factors probably play at least some role in this storage effect.

We feel that the three classes of explanation suggested here for the present findings require experimental investigation. It would also be desirable to relate these storage effects to phenomena such as the "decline of visual information" (Posner \& Keele, 1967), a process inferred from reaction time lasting well over a second. The present study meanwhile helps to extend the generality of the concept of short-term visual storage, while also showing the complex dependence of the phenomenon upon the stimulus conditions and task employed.

Broadly similar findings were obtained in each task for rare as opposed to frequent words. The unpredictable nature of many of the rare words used (e.g., catalpa, radicle) makes it unlikely that Ss perceived correctly only a few letters and guessed the remainder. The differences which were found between the two classes of words may be due to the approximately $20 \%$ longer single-flash recognition thresholds for the rare words. Particularly for Task 2 , the function relating storage time to stimulus duration is so steep that we might expect a sizeable increase in storage time from this factor alone. In Task 1 , the longer physical durations employed for the rare words may have caused the decreased storage times which were observed. However, we do not know whether word frequency per se affects the temporal properties of the visual system: McFarland's (1968) finding that the perceived simultaneity of letter forms is affected by their digram frequency suggests that it may.

The monotonic relationship between stimulus duration and threshold storage time found in Task 2 is not surprising, but the relationship found in Task 1 differs from that found by Haber and Standing (in press), whose data show a constant storage time (measured by perceived persistence) despite large changes in test stimulus duration. However, the stimuli used by Haber and Standing were well above the recognition 
threshold (corresponding to the flat right-hand portions of the Task-1 curves of Figs. 1 and 2); they also differed in complexity, contrast, and luminance from those employed here, so that we cannot identify the relevant factor responsible for this change.

Interestingly, our function relating storage time (Task 2) to stimulus duration, shown in Figs. 1 and 2, bears a resemblance to the function which relates perceived flash brightness to flash duration (Boynton, 1961). The latter function shows a monotonic increase in brightness as flashes are lengthened, followed by a point of inflection at about 80 -msec flash duration (the Broca-Sulzer effect), and a decline to an asymptotic level of about half the peak value thereafter. Our data follow this pattern quite closely.

\section{REFERENCES}

AVERBACH, E., \& CORIELL, A. S. Short-term memory in vision. Bell System Technical Journal, 1961, 40, 309-328.

BARLOW, H. B. Temporal and spatial summation in human vision at different background intensities. Journal of Physiology, 1958, 141, 337-350.

BOYNTON, R. M. Some temporal factors in vision. In W. A. Rosenblith (Ed.), Sensory communication. New York: Wiley, 1961. Pp. 739-755.

DAVY, E. The intensity-time relation for multiple flashes of light in the peripheral retina. Journal of the Optical Society of America, 1952, 41, 937-941.

HABER, R. N. Effect of prior knowledge of the stimulus on word-recognition processes. Journal of Experimental Psychology, $1965,69,282.286$.

HABER, R. N. Information processing analyses of visual perception: An introduction. In R. N. Haber (Ed.), Information processing approaches to visual perception. New York: Holt, Rinehart \& Winston, 1969. Pp. $1-15$.

HABER, R. N., \& HERSHENSON, M. Effects of repeated brief exposure on the growth of a percept. Journal of Experimental Psychology, $1965,69,40-46$.

HABER, R. N., \& STANDING, L. G. Direct measures of short-term visual storage. Quarterly Journal of Experimental Psychology, 1969 (Feb.).

HERSHENSON, M., \& HABER, R. N. The role of meaning in the perception of briefly exposed words. Canadian Journal of Psychology, $1965,19,42-46$.

JUNG, $R$. Neuronal integration in the visual cortex and its significance for visual information. In W. A. Rosenblith (Ed.), Sensory communication. New York: Wiley, 1961. Pp. 627-674.

KAHNEMAN, D. Time-intensity reciprocity as a function of luminance and figure-ground contrast. Vision Research, 1966, 6, 207-215.

McFARLAND, J. H. Effect of digram frequency on perception of a letter form's parts as simultaneous. Paper presented at Eastern Psychological Association Meeting, Washington, D.C., 1968.

POSNER, M. I., \& KEELE, S. W. Decay of visual information from a single letter. Science, 1967, 158, 137-139.

RATLIFF, F. Mach bands. San Francisco: Holden-Day, 1965.

SPERLING, G. The information available in brief visual presentations. Psychological Monographs: General \& Applied, 1960, 74 (Whole No. 498), 1-29.

SPERLING, G. A model for visual memory tasks. Human Factors, 1963 , 5, 19-31.

THORNDIKE, E. L., \& LORGE, I. The teacher's word book of 30,000 words. New York: Teacher's College, Columbia University, 1944.

NOTES

1. This research was partially supported by grants from the National Science Foundation, GB 5910, and the United States Public Health Service, MH 10753, to the second author.

2. Address: Department of Psychology, The University of Rochester, Rochester, N.Y. 14627.

3. Now at the University of Kansas.

(Accepted for publication September 12, 1968.) 